\title{
Development of Advanced Hot-Gas Desulfurization Processes
}

Type of Report:

Reporting Period

Principal Investigator

Date:

DOE Award Number:

Name and Address:

DOE Project Officer
Technical Progress Report, Report Number: 3

October 1, 1998 - March 31, 1999

K. Jothimurugesan

April 26, 1999

DE-FG26-97FT97276--03

Hampton University

Department of Chemical Engineering

Hampton, Virginia 23668

Dr. Kamalendu Das 


\section{DISCLAIMER}

This report was prepared as an account of work sponsored by an agency of the United States Government. Neither the United States Government nor any agency thereof, nor any of their employees, makes any warranty, express or implied, or assumes any legal liability or responsibility for the accuracy, completeness, or usefulness of any information, apparatus, product, or process disclosed, or represents that its use would not infringe privately owned rights. Reference herein to any specific commercial product, process, or service by trade name, trademark, manufacturer, or otherwise does not necessarily constitute or imply its endorsement, recommendation, or favoring by the United States Government or any agency thereof. The views and opinions of authors expresses herein do not necessarily state or reflect those of the United States Government or any agency thereof. 


\begin{abstract}
Advanced integrated gasification combined cycle (IGCC) power plants nearing completion, such as Sierra-Pacific, employ a circulating fluidized-bed (transport) reactor hot-gas desulfurization (HGD) process that uses 70-180 $\mu \mathrm{m}$ average particle size (aps) zinc-based mixedmetal oxide sorbent for removing $\mathrm{H}_{2} \mathrm{~S}$ from coal gas down to less than 20 ppmv. The sorbent undergoes cycles of absorption (sulfidation) and air regeneration. The key barrier issues associated with a fluidized-bed HGD process are chemical degradation, physical attrition, high regeneration light-off (initiation) temperature, and high cost of the sorbent. Another inherent complication in all air-regeneration-based HGD processes is the disposal of the problematic dilute $\mathrm{SO}_{2}$ containing regeneration tail-gas. Direct Sulfur Recovery Process (DSRP), a leading first generation technology, efficiently reduces this $\mathrm{SO}_{2}$ to desirable elemental sulfur, but requires the use of 1-3\% of the coal gas, thus resulting in an energy penalty to the plant. Advanced secondgeneration processes are under development that can reduce this energy penalty by modifying the sorbent so that it could be directly regenerated to elemental sulfur.
\end{abstract}

The objective of this research is to support the near and long term DOE efforts to commercialize the IGCC-HGD process technology. Specifically we aim to develop:

! optimized low-cost sorbent materials with 70-80 $\mu \mathrm{m}$ average aps meeting all Sierra specs.

! attrition resistant sorbents with $170 \mu \mathrm{m}$ aps that allow greater flexibility in the choice of the type of fluidized-bed reactor e.g. they allow increased throughput in a bubbling-bed reactor.

! modified fluidizable sorbent materials that can be regenerated to produce elemental sulfur directly with minimal or no use of coal gas.

The effort during the reporting period has been devoted to development of optimized low-cost zinc-oxide -based sorbents for Sierra-Pacific. The sorbent surface were modified to prevent sintering during pure air regeneration. Modifications were made to the sorbent to increase its ability to withstand high temperature and prevent loss of capacity by utilizing various textural promoters. Also several modified zinc-based sorbents prepared that can be regenerated to produce elemental sulfur directly with minimal use of coal gas. 


\section{TABLE OF CONTENTS}

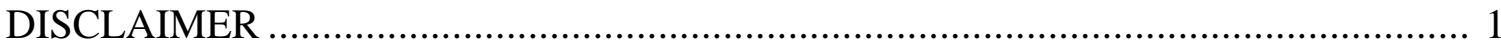

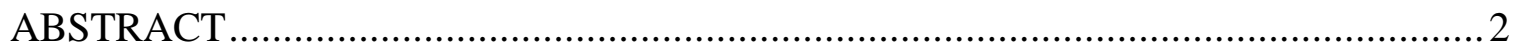

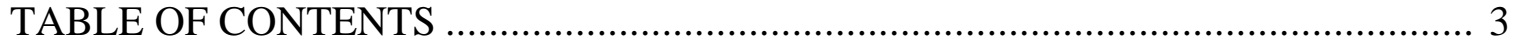

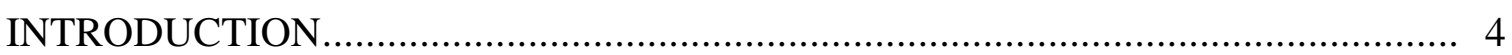

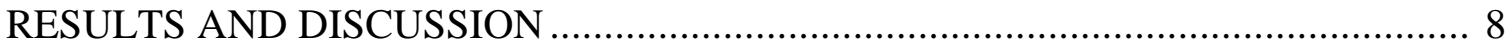

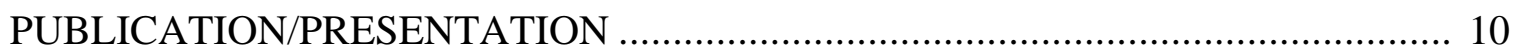




\section{Introduction}

Advanced integrated gasification combined cycle (IGCC) power plants are being developed to produce electricity from coal due to their potential for superior environmental performance, economics, and efficiency in comparison to conventional coal-based power plants. The U.S. Department of Energy (DOE), Federal Energy Technology Center (FETC) Clean Coal Technology program has led to the successful construction of two such advanced plants--Sierra Pacific and TECO, with shakedown and commissioning currently in progress. A key component of these advanced IGCC plants is a hot-gas desulfurization (HGD) process employing efficient regenerable zinc-based mixed-metal oxide sorbents that can remove the hydrogen sulfide $\left(\mathrm{H}_{2} \mathrm{~S}\right)$ in coal gas to $<20$ ppmv and that can be regenerated with air for multi-cycle operation as shown below for zinc oxide:

$$
\begin{array}{llll}
\mathrm{ZnO}+\mathrm{H}_{2} \mathrm{~S} & \rightarrow & \mathrm{ZnS}+\mathrm{H}_{2} \mathrm{O} & \text { (Sulfidation) } \\
\mathrm{ZnS}+(3 / 2) \mathrm{O}_{2} & \rightarrow & \mathrm{ZnO}+\mathrm{SO}_{2} & \text { (Regeneration) }
\end{array}
$$

For economic reasons, the sorbent must be able to maintain an acceptable level of reactivity over numerous absorption (sulfidation)-regeneration cycles.

This study is directed towards the development of sorbents for fluidized-bed reactors. The Sierra-Pacific plant employs the M.W.Kellogg (Kellogg) circulating fluidized-bed (transport) HGD process whereas the TECO plant employs the General Electric (GE) moving-bed HGD process. The key barrier issues facing the successful development of a fluidized-bed HGD process are chemical degradation, physical attrition, high regeneration light-off (initiation) temperature compared to sulfidation temperature, and high cost of the sorbent. Current leading first generation sorbents such as zinc titanate (ZT-4) typically prepared with an average particle size (aps) of $170 \mu \mathrm{m}$ using a granulator and Phillips Petroleum $₹$-Sorb III (175 $\mu \mathrm{m}$ aps) 
undergo significant chemical degradation, losing their reactivity and capacity by as much as $50 \%$ in just 50 cycles and they cost as much as $\$ 8-10$ per $1 \mathrm{~b}$. These sorbents also have very low attrition resistance compared to bench-mark fluid catalytic cracking (FCC) catalysts $(70-80 \mu \mathrm{m}$ aps) prepared by spray drying and employed in a petroleum refinery. The larger aps of $170 \mu \mathrm{m}$ results in reduced entrainment and allows greater throughput and flexibility in a bubbling-bed, but has not to date been successfully made using a spray drier. Also the regeneration light-off temperature of first generation zinc titanate sorbents is around $630-650^{\circ} \mathrm{C}$, which is unacceptably higher than the $480-550^{\circ} \mathrm{C}$ sulfidation temperature being employed at Sierra. To allow efficient heat integration, the sulfidation and regeneration light-off temperatures need to be close to each other.

Another inherent complication associated with all HGD processes is the disposal of a problematic dilute $\mathrm{SO}_{2}$ containing tail gas produced by air-regeneration of the zinc-based sorbent. The higher the oxygen concentration in the regeneration gas, the higher will be the $\mathrm{SO}_{2}$ concentration in the tail gas. However, the highly exothermic air regeneration reaction imposes an upper limit on the oxygen concentration that can be used. The GE moving bed reactor HGD process at TECO uses recycled $\mathrm{SO}_{2}$ as the diluent to moderate the reaction and produce a 12-14 volume $\% \mathrm{SO}_{2}$ tail gas. The Kellogg transport reactor HGD process at Sierra represents a major advancement in this regard because it enables efficient temperature control by rapidly circulating the sorbent and limiting the degree of regeneration, thus allowing the use of neat air as regeneration gas without recycle. However, higher $\mathrm{O} 2$ concentrations in the regeneration gas can promote sulfate formation in the sorbent which is undesirable. Even with neat air, a dilute $\mathrm{SO}_{2}$ tail gas containing a maximum of 14 volume $\% \mathrm{SO}_{2}$ is produced which needs to be disposed. Production of elemental sulfur from the $\mathrm{SO}_{2}$ is the most attractive option because it can be readily disposed, sold, stored and transported over long distances. The Direct Sulfur Recovery Process 
(DSRP) is a leading first generation process for converting the $\mathrm{SO}_{2}$ in the tail gas to elemental sulfur. In DSRP, the $\mathrm{SO}_{2}$ is catalytically reduced to elemental sulfur using a small slip stream of coal gas:

$$
\mathrm{SO}_{2}+2 \mathrm{H}_{2}(\text { or } 2 \mathrm{CO}) \rightarrow \quad 2 \mathrm{H}_{2} \mathrm{O}\left(\text { or } 2 \mathrm{CO}_{2}\right)+(1 / \mathrm{n}) \mathrm{S}_{\mathrm{n}}
$$

For each mole of sulfur, 2 moles of $\mathrm{H} 2+\mathrm{CO}$ are consumed. This represents an energy penalty to the IGCC plant. The higher the sulfur content of the coal, the higher is the consumption of coal gas by DSRP to produce elemental sulfur. Advanced second generation sulfur recovery processes are under development that aim to produce elemental sulfur rather than $\mathrm{SO}_{2}$ during sorbent regeneration by using $\mathrm{SO}_{2}$ itself as the regeneration gas. These advanced processes aim to develop and use a modified mixed-metal oxide sorbent in which one of the metals (M1) has favorable thermodynamics for regeneration by $\mathrm{SO}_{2}$ and yielding elemental sulfur directly where as the other metal (M2) is air regenerable to produce the $\mathrm{SO}_{2}$ needed for the first metal:

$$
\begin{array}{lll}
2 \mathrm{M} 1 \mathrm{~S}+\mathrm{SO}_{2} & \rightarrow & 2 \mathrm{M} 1 \mathrm{O}+(3 / \mathrm{n}) \mathrm{S}_{\mathrm{n}} \\
\mathrm{M} 2 \mathrm{~S}+(3 / 2) \mathrm{O}_{2} & \rightarrow & \mathrm{M} 2 \mathrm{O}+\mathrm{SO}_{2}
\end{array}
$$

with the net reaction being:

$$
2 \mathrm{M} 1 \mathrm{~S}+\mathrm{M} 2 \mathrm{~S}+(3 / 2) \mathrm{O}_{2} \quad \rightarrow \quad 2 \mathrm{M} 1 \mathrm{O}+\mathrm{M} 2 \mathrm{O}+(3 / \mathrm{n}) \mathrm{S}_{\mathrm{n}}
$$

This advanced process avoids the energy penalty associated with the coal gas consumption in the DSRP, however, the appropriate mixed metal oxide sorbent combination needs to be developed that yields the above overall stoichiometry during regeneration and at the same time can reduce the $\mathrm{H}_{2} \mathrm{~S}$ in the coal gas to less than 20 ppmv during sulfidation. 
In our previous work, an attrition resistant form of MCRH-61 was tested in the 2.0 inch HTHP fluidized-bed reactor simulating the Sierra-Pacific conditions for 10 cycles at sulfidation conditions of simulated Kellogg gasifier gas with $0.4 \% \mathrm{H}_{2} \mathrm{~S}$ at 18.8 atm pressure, $480-510^{\circ} \mathrm{C}$, and 15 slpm through a $145 \mathrm{~g}$ sorbent bed. The regeneration was conducted with pure air with an initial temperature of $480-510^{\circ} \mathrm{C}$. The $\mathrm{H}_{2} \mathrm{~S}$ breakthrough results indicated essentially complete removal of $\mathrm{H}_{2} \mathrm{~S}$ until a sharp breakthrough in all 10 cycles. The sorbent lost some capacity after the first cycle presumably due to pure air regeneration that increased the bed temperature to around $700^{\circ} \mathrm{C}$. After the first cycle, the capacity stabilized even with temperature excursions to $675-700^{\circ} \mathrm{C}$ and no attrition of the sorbent occurred in the 10 cycle test. Due to pure air regeneration, some sulfate formation did occur as seen from the $\mathrm{SO}_{2}$ evolution curves for cycles 2-10 during sulfidation. The sorbent lighted-off nicely at $482^{\circ} \mathrm{C}$. Overall the test is a success with potential for an optimized MCRH-61 to be a candidate for Sierra-Pacific. The cause of the reactivity drop during the first cycle and stabilization thereafter needs to be evaluated. The sulfate formation on the sorbent needs to be minimized during pure air regeneration and the overall preparation needs to be optimized to reduce cost down to less than $\$ 3.00$ per lb.

To summarize, the short-term and long-term DOE research and development needs in fluidized-bed HGD processes include:

! optimized sorbents with 70-80 $\mu \mathrm{m}$ aps meeting all Kellogg specifications for their transport reactor HGD process at the Sierra-Pacific power plant

! $\quad 170 \mu \mathrm{m}$ aps attrition resistant sorbents to allow greater flexibility, reduced entrainment, and increased throughput in bubbling-bed reactors.

! fluidizable sorbent materials that can not only reduce $\mathrm{H}_{2} \mathrm{~S}$ to $<20$ ppmv but at the same time be directly regenerable to elemental sulfur without coal gas consumption as in DSRP 


\section{RESULTS AND DISCUSSIONS}

The project consists of four experimental tasks (Tasks 1-4) addressing the contract objectives described above.

Task 1: Development of Sorbent for Sierra-Pacific

Task 2: Bubbling-Bed Reactor Sorbents

Task 3: Advanced Sulfur Recovery Sorbents

Task 4: Sorbent Characterization

\section{Task 1: Development of Sorbent for Sierra-Pacific}

Several zinc-based sorbents have been prepared and tested. The sorbent surface were modified to prevent sintering during pure air regeneration. Modifications were made to the sorbent to increase its ability to withstand high temperature and prevent loss of capacity by utilizing various textural promoters. These sorbents are designated as FHR sorbents. Based on the screening study, the FHR-32 sorbent showed the best suifidation performance. Currently, plans are underway to test this sorbent for about 50 cycles in a multicycle run.

\section{Task 2: Bubbling-Bed Reactor Sorbents}

Several zinc-based sorbents have been prepared and tested. The FHR-33 sorbent was prepared using spray drier. The pore volume the sorbent is $0.37 \mathrm{~mL} / \mathrm{g}$. The attrition index is 40.9 . Sulfidation tests were carried out with a sulfidation gas containing (vol \%): $\mathrm{H}_{2} \mathrm{~S}=1, \mathrm{H}_{2}=10$, $\mathrm{CO}=15, \mathrm{CO}_{2}=5, \mathrm{H}_{2} \mathrm{O}=15$ and balance $\mathrm{N}_{2}$. The gas hourly space velocity for the tests was about $2500 \mathrm{~h}^{-1}$ both in sulfidation and regeneration. The sulfidation was carried out at $538^{\circ} \mathrm{C}$. Regeneration between cycles was conducted with pure air at $600^{\circ} \mathrm{C}$. Figure 1 shows the sulfidation performance of the FHR-33 sorbents. The pre-breakthrough level was less than 60 
ppm. There is no decline in activity in 5-cycles tested.

\section{Task 3: Advanced Sulfur Recovery Sorbents}

Several sorbents has been prepared and tested. Sulfidation tests were carried out with a sulfidation gas containing ( $\mathrm{vol} \%$ ): $\mathrm{H}_{2} \mathrm{~S}=0.4, \mathrm{H}_{2}=10, \mathrm{CO}=15, \mathrm{CO}_{2}=5, \mathrm{H}_{2} \mathrm{O}=5$ and balance $\mathrm{N}_{2}$. The gas hourly space velocity for the tests was about $2500 \mathrm{~h}^{-1}$ both in sulfidation and regeneration. The sulfidation was carried out at $450^{\circ} \mathrm{C}$. Figure 2 shows the sulfidation performance of the FHR sorbents. The pre-breakthrough level was less than 50 ppm. Both FHR7 and FHR-8 showed better sulfidation performance. The BET surface areas of the fresh sorbents are shown in Table 1.

\begin{tabular}{|l|l|}
\hline Sorbents & BET Surface Area, $\mathrm{m}^{2} / \mathrm{g}$ \\
\hline FHR-1 & 165.1 \\
\hline FHR-2 & 162.7 \\
\hline FHR-3 & 165.7 \\
\hline FHR-4 & 165.9 \\
\hline FHR-5 & 141.9 \\
\hline FHR-6 & 106.8 \\
\hline FHR-7 & 120.2 \\
\hline FHR-8 & 95.2 \\
\hline
\end{tabular}

\section{Task 4: Sorbent Preparation and Characterization}

This task provides support to each of the previous tasks. The following analytical techniques are used to characterize the fresh, sulfided and regenerated sorbents on an as needed basis.

1. X-ray Diffraction (XRD) for crystalline phase.

2. Surface area measurement using BET method.

3. Hg-porosimetry for pore volume, bulk density, average pore diameter and pore size distribution determination. 
4. Atomic Absorption (AA) Spectrometry for elemental composition analysis.

5. 3-hole attrition tester for attrition measurement

\section{FUTURE WORK}

Work will continue to develop attrition-resistant zinc-oxide based sorbents for fluidized bed applications.

\section{PUBLICATION/PRESENTATION}

1. K. Jothimurugesan and S.K. Gangwal " Advanced Hot-Gas Desulfurization Sorbents for Transport Reactor" 1998 Spring National AIChE Meeting, New Orleans, LA, March 8$12,1998$.

2. K. Jothimurugesan and S.K. Gangwal., "Development of Advanced Hot-Gas Desulfurization Processes," Advanced Coal-Based Power and Environmental Systems '98 Conference, Morgantown, WV, July 21-23, 1998.

3. S.K. Gangwal, J.W. Portzer, T.P. Dorchak and K. Jothimurugesan, "Advanced Hot Gas Desulfurization Process with Sulfur Recovery," Gas Cleaning at High Temperatures, Karlsruhe, Germany, September 22-24, 1999. Abstract Accepted. 
Time Schedule for Year 2 (October 1, 1998 -September 30, 1999)

\begin{tabular}{|l|c|c|c|c|}
\hline \multicolumn{1}{|c|}{ TASK } & \multicolumn{3}{c|}{ Quarter } \\
\cline { 2 - 5 } & 1 & 2 & 3 & 4 \\
\hline Task1: Development of Sorbent For Sierra-Pacific & & & & \\
\hline Task 2: Bubbling-Bed Reactor Sorbent & & & & \\
\hline Task 3: Advanced Sulfur Recovery Sorbents & & & & \\
\hline Task 4: Sorbent Characterization & & & & \\
\hline Semi-Annual Report & & & & \\
\hline
\end{tabular}




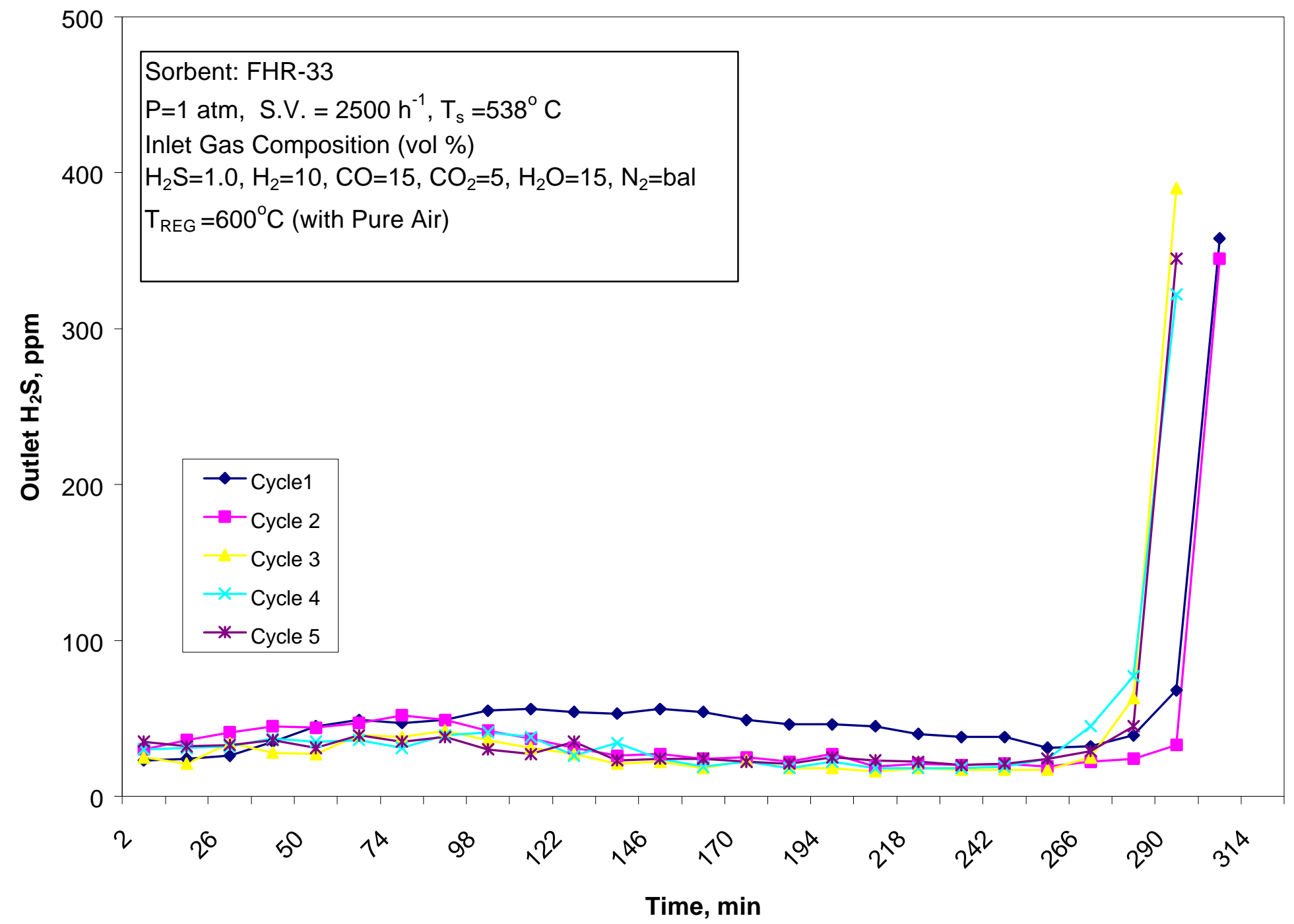

Figure 1. $\mathrm{H}_{2} \mathrm{~S}$ Breakthrough Curves in Successive Sulfidation Cycles of Sorbent FHR-33 


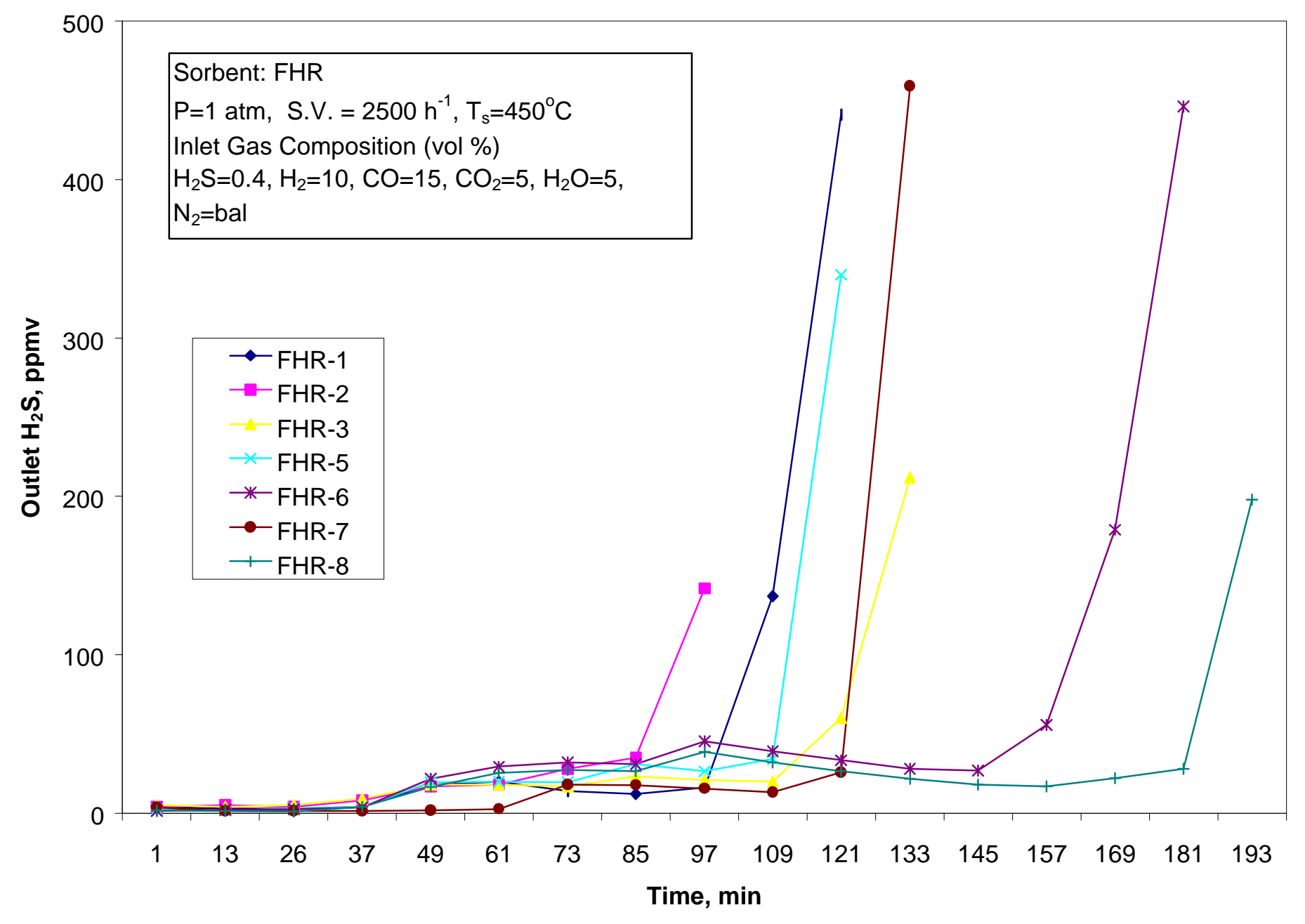

Figure 2. $\mathrm{H}_{2} \mathrm{~S}$ Breakthrough Curves in Successive Sulfidation Cycles of FHR Sorbents 